\title{
Important topics and conclusions from the 29th International Vienna Motor Symposium ${ }^{1)}$
}

\begin{abstract}
For many years Vienna Motor Symposium has been recognized as one of the most important networking events for specialists in engine and vehicle research and production worldwide. The most important questions related to the present and future development of means of transport, drivetrains, energy sources and conversion issues, not to mention the pollution generated by transport have been discussed. Some important future trends and strategies have also been identified and defined. This paper presents the main issues that were reported and discussed in the Symposium held in April 2008.
\end{abstract}

\section{Introduction}

As every year the leading automotive engineers from all over the world presented at the 29th International Vienna Motor Symposium in April 2008 their ideas and conclusions about recent engine development and gave an outlook on future trends in the automotive engineering industry.

Over 1000 participants from many countries have been welcome by Prof. H.P. Lenz, president of the Austrian Society of Automotive engineers (ÖVK) and president of this conference since many years.

In the opening address Prof. Lenz stressed the regrettable fact, that the tremendous progress made over the past few decades with regard to the reduction of pollutant emissions and fuel consumption of our engines was not sufficiently acknowledged by politicians and partly also by the general public. Instead, time and again unjustified horror scenarios about particulate emissions or gases affecting the climate are disseminated.

In Prof. Lenz's view, a major threat in the debate about the effects of $\mathrm{CO}_{2}$ on the climate was posed by the concerns about climate change and greenhouse gases which had in the meantime emerged as an independent issue. Alongside alarmed scientists, others benefiting from the concerns about the climate dominated the scene. According to estimates, today euro 140 billions have been invested in

1) This paper is based on the Conference Report prepared by Prof. H.P. Lenz and published in the Motorentechnische Zeitschrift in August 2008; this version, reprinted with the Author's and MTZ Editors' consent, is an abridgement due to a limited capacity of our magazine (Editors). so-called climate funds in the EU which, it is argued, "seek to play an active role in the fight against climate change in a sustainable manner". These funds are, of course, not only preoccupied with the climate but are also very much interested in realizing price rises and therefore keep this topic boiling.

Quite frequently politicians use the topic of climate change for building up their own profile. And when the climate is to be protected, all politicians seek to build up their reputation as saviours, assuming that nobody could call their honest intentions on this into question. Organizations active in green politics are trying to use moralizing tactics to influence the population and to dictate the rules of cars

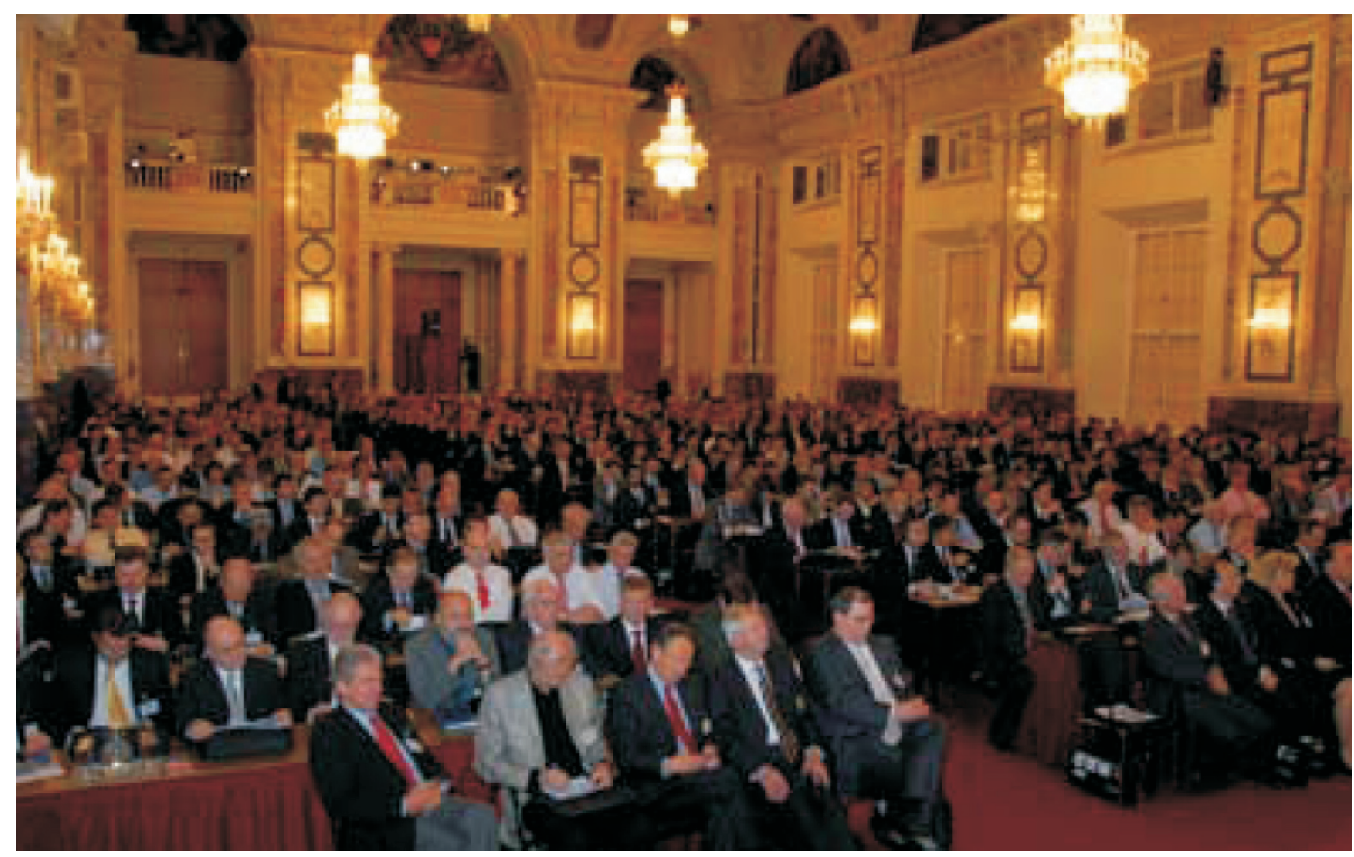

exploitation. The Czech President, Vaclav Klaus, recently coined the memorable phrase "What is at stake today is not the climate but the freedom of all of us".

It has been common knowledge for quite some time now that in the automotive industry the reduction of emissions by one tonne of $\mathrm{CO}_{2}$ costs 20 times more than in any other industry. Cars, while exhibiting ever higher fuel economy, are caught in bumper to bumper traffic for ever longer times 
because the infrastructure is insufficient. Also in the future, it must be left to the discretion of consumers which car they want to buy, a large one or a small one.

Prof. Lenz expressed his hope that this Symposium would, over and above its primary task of acting as a forum for the discussion of progress in automotive engineering, also provide relevant information on all these issues to the general public.

\section{Plenary Opening Session}

Senator Ing. S. Wolf, CEO, Magna International, Oberwaltersdorf, presented the lecture "Russia - a New Market with New Opportunities and Challenges". He explained that alongside China and Brazil, Russia ranked amongst the markets with the highest growth potential for the automotive engineering industry. Whereas international automobile manufacturers building up production capacity in Russia were facing the need for a modern, functioning supplier base meeting international standards.

T.G. Stephens, Executive Vice-President - Global Powertrain and Global Quality, General Motors Corporation, USA, reported "GM's Advanced Propulsion Technology Strategy - Solutions for Reduced $\mathrm{CO}_{2}$ Emissions and Energy Diversity". He pointed out that GM endeavoured to make a contribution to the sustainability of energy systems by developing a host of different technologies. GM, he stressed, concentrated on a strategy that consisted of four elements:

- Increasing the efficiency of engines and transmission systems: introduction of pioneering drivetrain technologies offering improved fuel economy and lower emissions.

- Alternative fuels: intensified use of propulsion systems suitable for bio-fuels (ethanol, E 85, bio-diesel).

- Electrification of the drivetrain: Focus on the electrification of vehicles through the introduction of hybrid and plug-in hybrid technologies as well as the use of electrical propulsion systems.

- Fuel cells: development of a production - standard, fuel cell system for cars, using hydrogen as a source of energy. GM will launch these product innovations via its global organization.

K. Döhmel, CEO, Deutsche Shell Holding GmbH, Hamburg, dealt with the topic "Future Mobility from a Fuels Perspective":

Worldwide demand for mobility will soar. Already today, road traffic uses up nearly $50 \%$ of global oil production. Energy supply to road transport must be seen in the context of global energy supply. Shell assumes three "hard facts": - accelerated expansion of worldwide demand for energy - the difficulty of meeting this demand by means of oil that can be easily extracted, as well as

- a further rise of carbon dioxide emissions worldwide.

Road traffic accounts for some $25 \%$ of $\mathrm{CO}_{2}$ emissions from sources of energy - and the use of motor cars and mobility will become ever more widespread in all parts of the world. Fuels can contribute significantly to solving the global problem of energy scarcity and the emission of greenhouse gases. In close co-operation with leading car-makers, Shell focuses particularly on three options:
- synthetic fuels produced from natural gas (GTL),

- second generation biogenic fuels, and

- further developments in currently available hydrogen technology.

Prof. Dr.-Ing. K.V. Schaller, Director of Engineering and Procurement, MAN Nutzfahrzeuge AG, dealt with the topic "Commercial Vehicle Engineering: Energy Efficiency and Fuel Strategies". Commercial vehicles account for the same share of global $\mathrm{CO}_{2}$ emissions as cars - namely approximately $6 \%$ each. With the expected growth in this market segment due to macroeconomic trends, the commercial vehicle industry will have to come up with even better solutions in order to heighten the efficiency of road transport even further. To this end, the question must be answered as to how minimum energy input can be assured for each tone-kilometre, which is our performance unit. It is gratifying to see that a wide variety of efficient approaches has been devised - the strongest driving forces behind these are vehicle dimensions, weight and the related aerodynamic parameters. However, political support for these measures is needed just as urgently as for the creation of the necessary infrastructure. In parallel, fuel strategies with a long-term potential for success must be implemented; such strategies must not only be feasible in laboratories but must also prove their practical value in threshold countries where they have the potential for low-cost and reliable use as an alternative to conventional fuels.

It should also be borne in mind that emission standards around the world are rapidly becoming ever more stringent. The threshold countries, in particular, are following the lead of the technologically advanced countries at ever shorter intervals. Today it is virtually impossible to pass on "old technologies" to these regions.

\section{Environment}

Prof. Dr. h.c. R. Zellner, University of Duisburg presented "Climate and the Role of $\mathrm{CO}_{2}$ " and expressed the opinion that carbon dioxide, which has the strongest impact on the climate, is at the centre of the debate.

The large majority of climate researchers who cooperate in the Intergovernmental Panel for Climate Change (IPCC) attribute the temperature rise to the continuous increase in anthropogenic carbon dioxide concentrations since the middle of the past century at the latest. The critics of the IPCC argue, on the other hand, that natural factors such as solar radiation play a more important role and deny the great influence of carbon dioxide on the climate and the existence of the anthropomorphic greenhouse effect.

This dispute would probably go largely unnoticed if it did not have very severe consequences: the probable further development of the climate, assuming a carefree businessas-usual scenario for the utilization of fossil raw materials used as sources of energy and the concomitant emissions of $\mathrm{CO}_{2}$, would, according to the IPCC, lead to an additional warming of 2.5 to $4.5^{\circ} \mathrm{C}$ by the end of this century. As such an extent of warming would seriously jeopardize living conditions on our planet, the need for action in order to bring about a substantial reduction of global $\mathrm{CO}_{2}$ emissions appears indispensable. Such action, which would result in 
a massive intervention in our stationary or mobile energy supply system, would not be necessary if the influence of $\mathrm{CO}_{2}$ on the climate were to be shown as overestimated, as propounded by critics of the IPCC.

Dr.-Ing. E.h. J. Liebl, Dr. C. Cozzarini, Dipl.-Ing. G. Schmitz, BMW Group, presented: " $\mathrm{CO}_{2}$ Regulations Worldwide - A Challenge for the Automotive Industry?".

The interaction of available technologies, acceptance by the markets and statutory requirements constitute the prerequisite for a rapid spreading of $\mathrm{CO}_{2}$-reducing measures in world markets. In order to be able to devise such measures at the level of quality which customers have come to expect, appropriate lead times are necessary. Responsible legislation must take such lead times into account.

In addition, $\mathrm{CO}_{2}$ reduction efforts must go hand in hand with characteristics demanded by customers, such as safety, convenience and dynamic driving pleasure; otherwise, these engines would fail in the marketplace. Internationally harmonized $\mathrm{CO}_{2}$ emission legislation with well-balanced time-tables oriented primarily to the individual potentials for efficiency increases in the various market segments are a key factor for success.

Dr.-Ing. J. Schommers, Dr.-Ing. A. Lingens, Dr.-Ing. H. Breitbach, Dipl.-Ing. T. Betz, Daimler AG, Stuttgart, reported: "Innovative Diesel Concepts - A Sustainable Path to $\mathrm{CO}_{2}$ Reduction".

In recent years, enormous improvements in thermodynamically relevant diesel engine components (turbocharging, fuel injection and exhaust gas recirculation) and designs have led to significant improvements in fuel economy, performance and exhaust emissions. Despite the vast torque potential, however, further improvements in diesel engine fuel economy via load-point shifting were not possible due to emission requirements and driveability demands of customers. These limits can now be significantly shifted through targeted thermodynamic designs and new, innovative technological components. The new four-cylinder concept presented here permits considerably reduced fuel consumption, by means of operating-point shifting while retaining driveability characteristics typical of the vehicle class. Mr. Schommers discussed the premises and methods for downspeeding and downsizing approaches, described the challenging thermodynamic requirements, and explained the details of this innovative concept. Fuel injection and turbocharging techniques are the main elements on which this concept is based.

\section{Simulation}

Dr. C. Trapp, Dipl.-Ing. P. Feulner, Ricardo Deutschland GmbH, J. Andersson, S. Wrighley, B. Gilchrist, Ricardo UK, presented: "A Set of Virtual Tools and Techniques for the Development of Future Low Emission Vehicles with Internal Combustion Engines - Strategy, Overview and Example Application to the Modeling of Fouling in EGR Systems".

The development of future low-emission vehicles with internal combustion engines as well as their control units and diagnostic systems calls for an integrated set of tools and techniques under ever more stringent time and cost constraints for representing a virtual vehicle with control and calibration concepts and a virtual application. Thus it is possible in an early phase of the development process to investigate the vehicle configuration and component design with special focus on emissions (especially of nitrogen oxides and particulates), fuel consumption and driveability for target attainment over statutory and customer-relevant driving cycles.

Dipl.-Ing. K. Cornelsen, Prof. Dr.-Ing. T. Form, Brunswick University of Technology; Dipl.-Ing. D. Jänsch, Dipl.-Ing. W. Nietschke, Dr.-Ing. T.-M. Wolter, IAV GmbH, Berlin/Gifhorn, reported: "A New Methodology for the Development of Hybrid Powertrains".

Hybrid powertrains are highly complex systems. Their efficiency depends largely on the right design of components and their accurate coordination. In selecting the operating strategy, the type of operation as well as the entire system, consisting of environment, traffic, driver, vehicle and powertrain, must be taken into account. Today, powertrain systems are developed off-line in a full-vehicle simulation process that predicts the quantitative values of a hybrid concept's handling characteristics with relative accuracy already in the design phase. Qualitative values and actual driving feel, in contrast, are described inadequately. To date, it has only been possible to show these at a later phase of the development process by constructing driveable prototypes.

Dipl.-Ing. T. Dobes, Dr. P. Kapus, Dr. P. Schöggl, Dipl.Ing. H. Jansen, Dipl.-Ing. E. Bogner, AVL List GmbH, Graz, presented: " $\mathrm{CO}_{2}$ Reduction in Everyday Operation - Influence of Engine Calibration".

"Downsizing" and "downspeeding" by means of turbocharging and direct injection technologies offer a high potential for reducing fuel consumption of gasoline engines. The resulting additional system costs are moderate compared to other technological approaches. Low fuel consumption values which can be achieved over the standard driving cycle can be reached in everyday operation only if low enrichment under full-load and good transient response is combined with long gear ratios. The lecturer compared different vehicles with four-cylinder turbocharged engines over the entire NEDC and a customer consumption cycle in which fuel saving and sporty driving styles were tested.

\section{New Diesel Engines}

Dipl.-Ing. R. Bauder, Dipl.-Ing. A. Fröhlich, Dipl.-Ing. W. Hatz, Dr.-Ing. H. Marckwardt, Dipl Ing. E. Michels, Audi AG, Neckarsulm/Ingoldstadt, presented: "The New Audi 6.0 Litre V12 TDI, the Ultimate Performance Diesel".

With its newly developed 6.0 Litre V12 TDI engine, Audi has presented the world's most powerful passenger car diesel engine with maximum torque. Based on state-of-the-art diesel technologies, a power output of $368 \mathrm{~kW}$ and a maximum torque of $1000 \mathrm{~N} \cdot \mathrm{m}$ has been achieved. In combination with a diesel particulate filter, the Audi Q7 complies with the EU5 emission standards. Its fuel consumption of just 11.9 litre per $100 \mathrm{~km}$ in the MVEG test is extremely low for a sports utility vehicle showing this level of performance. The engine 
runs outstandingly smoothly, as can be expected of a typical twelve-cylinder unit.

Although the engine incorporates a number of specific twelve-cylinder design features, including a $60^{\circ}$ cylinder angle, it also uses many synergies shared with the familiar Audi V6 and V8 TDI engines. It rounds off the top end of the Audi range of the $\mathrm{V}$-configuration engines.

Dipl.-Ing. B. Heil, Dipl.-Ing. W. Schmid, Dipl.-Ing. M. Teigeler, Dipl.-Ing. U. Weiß, Dipl.-Ing. S. Melcher, M. Groeneweg, Daimler AG, Stuttgart/Detroit, reported: "New Daimler Heavy Duty Commercial Vehicle Engine Series - Introduction of the 14.8 Litre EPA07 Engine for Freightliner".

As part of the global standardization of its Group portfolio, Daimler AG are currently developing a new Heavy Duty Engine Platform (HDEP) for use in heavy-duty commercial vehicles. With the presentation of the Detroit Diesel DD 15, the first engine of this engine family with a displacement of 14.8 Litre was launched in the North American market.

Additional variants of this platform with displacements of 15.6, 12.8 and 10.6 Litre will follow. These engines will then be gradually introduced in all Daimler AG trucks. The first vehicles to be equipped with the new engines will be the Freightliner, Western Star and Sterling brands, which had previously been fitted with S60 engines. Subsequently, from 2009 onwards, FUSO trucks which have been available with the $6 \mathrm{M} 70$ in the Asian market will follow suit. These new engines will also replace the currently successful BR500 and OM457 models of Mercedes-Benz trucks in Europe. As a result of these changes, Daimler's portfolio will be consolidated worldwide. All displacement categories of the heavy-duty engine platform are in-line six-cylinder engines in which, alongside economic aspects such as full commonality across all brands and engine sizes, special emphasis is placed on technological progress.

Dipl.-Ing. J. Hadler, Dipl.-Ing. F. Rudolph, Dipl.-Ing. R. Dorenkamp, Dipl.-Ing. H. Stehr, Dr.-Ing. T. Düsterdiek, Dipl.-Ing. J. Hilzendeger, Dipl.-Ing. D. Mannigel, Dr. rer. nat. S. Kranzusch, Dipl.-Ing. B. Veldten, Dr. M. Kösters, Dipl.-Ing. A. Specht, Volkswagen AG, Wolfsburg, presented "Volkswagen's New 2.0 Litre TDI Engine Fulfils the Most Stringent Emission Standards".

The new 2.0 Litre 4V TDI engine with common rail technology, which will be available in the VW Jetta in the USA from mid-2008 onwards will meet the world's most stringent emission standards as set forth in the BIN5/LEV2 emission legislation. In addition to improvements in engine design, the common rail engine used in the Volkswagen Tiguan and the Audi A4 was further developed to include an $\mathrm{NO}_{\mathrm{x}}$ exhaust gas after-treatment system.

The special technical features of this engine include an optimised injection system, a low pressure exhaust gas recirculation system, an innovative cylinder pressure regulation concept as well as a $\mathrm{NO}_{\mathrm{x}}$ storage catalytic converter. These new engine components called for the development of new control algorithms and intensive co-ordination of parameters for the completely new combustion process. Thus a new hardware and software architecture had to be designed for the engine control unit, which has in the meantime been made ready for series production.

\section{Mixture Formation}

Dr. R. Leonhard, J. Warga, Dr. T. Pauer, F. Boecking, Dr. D. Straub, Robert Bosch GmbH, Stuttgart, presented: "Bosch 2000 Bar Common Rail System for Passenger Cars and Light Duty Vehicles".

Thanks to piezo technology, the 2000 bar injection system of Bosch, which has been series-produced since 2007, is characterized by highly flexible, high-precision dosing of diesel fuel at all operating points. Together with the new generation of high pressure pumps with maximum hydraulic efficiency, this fuel injection system contributes optimally to engine design solutions which assure compliance with the lowest emission levels in Europe and the US and a further reduction of $\mathrm{CO}_{2}$ emissions. The lecturer described the complete system with its key components and core functions as well as measures for pressure boosting, multiple injection with minimum injection intervals and improved hydraulic efficiency. In his outlook to the future, the lecturer explained how Bosch improved its common rail injection technology further in order to assure the great success of diesel engines in Europe, America and Asia.

Dr. D. Schöppe, M. Hardy, S. Zülch, D. Geurts, Delphi Corporation, Bascharage/ Blois, reported: "Exceeding Customer Expectations with the Innovative Direct Acting Diesel Fuel Injection System. Unique Advantages of a Breakthrough Technology“.

With its direct-drive common rail injector, Delphi is starting to implement a highly innovative concept for fuel injection in series-production. In Delphi's direct-drive common rail injector, the injector needle is activated by means of a piezo-ceramic actuator and is no longer moved by means of a conventional electro-hydraulic system. This permits faster and more accurate fuel injection into the combustion chamber combined with significantly improved spray quality. In addition, the fastest needle opening and closing times can be achieved irrespective of injection pressure. This concept has resulted in an impressive reduction of raw emissions, higher power density and lower fuel consumption.

Dipl.-Ing. S. Bauer, Dr. rer. nat. H. Zhang, Dipl.-Ing. R. Pirkl, Dr.-Ing. A. Pfeifer, Dr.-Ing. K. Wenzlawski, Dipl.Ing. H.-J. Wiehoff, Continental AG, Regensburg, presented: "A New Piezo Common Rail Injector with Direct Drive and Closed Loop Functionality: Concept and Engine Benefits".

With the new 2000 bar piezo direct-drive common rail injector and the closed-loop injector featuring this concept for the first time, a new building block has been created for lowering emissions. The new concept offers a wide range of options for shaping reproducible injection rate curves and thus constitutes an alternative to conventional multiple injection patterns. By mapping injection needle positions during the injection process it is possible for the first time to close the volume control circuit. The small drifts and sample-to-sample deviations which cannot be entirely eliminated despite the stable hydraulic design are reliably 
identified and compensated. Thus the system does not need to be fitted with cost-intensive additional closed-loop circuits controlled by cylinder pressure or lambda probe signals as with conventional diesel combustion processes if this injector system is used.

\section{Powertrain Electrification}

Dr. G. Schmidt, Vice President, Ford Motor Company, Dearborn, USA, presented: "Energy Storage and the Path to Sustainable Transportation".

The continued surge of energy demand and consumption presents major challenges to society and the environment. Security of energy supply and global climate change, which are also caused by the increased combustion of fossil fuels in order to meet growing energy demand, today have become major concerns. As individual mobility assured by the use of motor cars contributes to energy consumption as well, the automotive engineering industry, like other business sectors, faces the challenge to come up with solutions that will guarantee sustainable mobility. The social, economic and ecological aspects of sustainable individual mobility can be defined - in outline - by such key parameters as the need to be energy-efficient, environmentally friendly, convenient, affordable and socially acceptable. Starting with the primary sources of energy, the lecturer paid special attention to these parameters and evaluated the significance of potential future sources of special parameters of the different sources of energy and outlined the implications of their storage in the vehicle, before he subsequently assessed their sustainability in the well-to-wheel chain. In this context, he also examined the demands made upon, and challenges presented to, hybrid electric vehicle (HEV), plug-in hybrid electric vehicle (PHEV) and battery-driven electric vehicle (BEV) systems.

Univ.-Prof. Dr. G. Hohenberg, Darmstadt University of Technology, presented: "Replacing the Hybrid by Intelligent Driving?".

At the 27th Vienna Motor Symposium, held in 2006, the hybrid drive of the Lexus 2x400 was already described from a theoretical and practical perspective. This year's presentation, which described the new Lexus LS 600h, was a follow-up to this topic. The E-CVT transmission is designed as a so-called two-mode concept, which brings down consumption to acceptable levels even at high driving speeds.

By further improving the engine, it was possible to enhance the comfort of the hybrid system. The start/stop behaviour was even further optimised as compared to the very outstanding performance of the RX $400 \mathrm{~h}$. As far as this feature is concerned, the Lexus LS 600h L represents the state-of-the-art. When comparing the Lexus LS 600h L with other premium class vehicles in terms of fuel economy, it becomes obvious that the benefits of the hybrid concept cannot be offset, not even by an intelligent driver using foresight.

The far better fuel economy of hybrid engines in real traffic is obvious, not only as compared to gasoline engines but also to diesel engines. The more foresighted the driving style, the higher will be the saving potential compared to diesel engines, which are often considered as an alternative.

The reduction of $\mathrm{CO}_{2}$ emissions which can be attained by intelligent driving in the urban cycle correspond to close to $30 \%$, whereas with a dynamic driving style this difference shrinks to about $10 \%$. This explains the sometimes widely differing test results for hybrid and diesel cars reported by the press.

The hybrid is, of course, no panacea for solving the current $\mathrm{CO}_{2}$ problem. Concluding, the lecturer explained that the use of hybrid and/or diesel cars will not be sufficient to achieve the $\mathrm{CO}_{2}$ target values. Under the aspect of "intelligent simplicity", the logical consequence can only be the downsizing of vehicles.

Dr. T. Weber, Member of the Board of Management, Daimler AG, Stuttgart, reported: "Electrified Vehicle - a Trend for the Future".

Hybrid technology forms an integral part of the drive strategy for sustainable mobility, as internal combustion engines will remain the dominant drive system in the coming decades. Hybridisation will allow further efficiency gains and thus also higher fuel efficiency. For this reason, Daimler, in principle, is developing only vehicles and engines which are suitable for hybridisation. Nevertheless, hybrid vehicles must be seen realistically in terms of their market potential, production capacity and the fuel economy benefits they offer. At present, hybrid vehicles account for approximately 500,000 units of total sales of 57.7 million passenger cars world-wide. This corresponds to a market share of a mere 0.9 per cent of global vehicle sales.

Market forecasts for the US assume a market share of between 6 and $30 \%$ by the year 2020. An examination of available production capacity also shows that hybridisation offers only one possible option among many: experts anticipate an expansion of hybrid production capacity to about one million units annually by 2010 . This figure corresponds to slightly less than two per cent of annual worldwide demand for passenger cars.

Daimler believes that the combination of hybrid modules with clean Blue TEC diesel technology offers the greatest potential. Mercedes-Benz will launch its first passenger car with a Blue Tec hybrid drive system in 2010.

\section{Supercharging}

Prof. Dr.-Ing. H. Zellbeck, Dipl.-Ing. T. Ross, Dipl.-Ing. C. Guhr, Dresden University of Technology, presented: "New Methods for Proper Boosting Systems“.

Today, single-stage charging systems can often no longer meet customers' demands. In contrast to gasoline engines, diesel engines are predestined for regulated two-stage turbocharging due to their lower exhaust gas temperatures and reduced sensitivity to residual gas. As a result of their complexity, dimensioning and testing of modern charging systems always require extraordinary efforts.

Dr.-Ing. H. Németh, Prof. Dr.-Ing. L. Palkovics, KnorrBremse R\&D Center, Budapest; Prof. Dr.-Ing. H. Hitziger, Dr.-Ing. E. Gerum, Knorr-Bremse SfN GmbH, Munich; Prof. Dr.-Ing. R. Flierl, Kaiserslautern University of Technology, presented: "PBS - A New Solution to Improve Dynamic Torque Rise and Emission Behaviour of Supercharged Diesel Engines by Electronic Controlled Air Injection”. 
Efforts to improve the dynamic response of supercharged internal combustion engines by adding compressed air are well known. However, these efforts showed only limited success, since the response time of the applied components was too long. This resulted in high demand for additional compressed s-p air, which series-produced compressors were unable to deliver.

A favourable combination of two parallel technological developments in the past few years (i.e. electronic diesel injection systems for commercial vehicles, common rail injection, and highly dynamic, electronically controlled components for brakes used in commercial vehicles) resulted in the development of a pre-production system based on series-produced components which can be easily integrated into the charge air system. The new system resulted in a significant improvement of the response and acceleration characteristics of the engine and the vehicle. The minimised additional quantity for compressed air that is required can normally be supplied through the optimisation of a series-produced compressed air unit. The lecturer described the design and functioning of the system and reported the results of simulation studies, as well as dynamometer and driving tests.

Dipl.-Ing. A. Königstein, Dipl.- Ing. P.-I. Larsson, General Motors Powertrain Europe, Rüsselsheim; Prof. Dr. U.D. Grebe, Dr. K.-J. Wu, General Motors Powertrain, Pontiac, USA, presented: "Differentiated Analysis of Downsizing Concepts".

In downsizing, a naturally aspirated engine is replaced by a boosted engine having a smaller displacement. In the past, downsizing was mainly used for increasing maximum performance whereas nowadays reducing fuel consumption by downsizing is gaining increasing importance.

A detailed analysis of fuel consumption maps shows that turbocharged gasoline engines have a higher brake specific fuel consumption than naturally aspirated engines. Only when a naturally aspirated engine and a downsized turbocharged engine are compared at the same torque will the turbocharged engine show better fuel consumption in the low to mid torque range of the engine map. The reason is that the engine with the smaller displacement is operated at a higher bmep, which is inversely proportional to the displacement. This load range can be widened by selecting a small displacement for the turbocharged engine. A downsizing factor (displacement of NA engine divided by the displacement of turbo engine) of at least 1.4 is recommended. In order to achieve better fuel economy in the vehicle as well, the overall gear ratio must be decreased. This approach makes sense as the rated engine speed of turbocharged engines is generally lower than that of naturally aspirated engines, and the torque of turbocharged engines is higher and wider than that of naturally aspirated engines having the same output. The maximum gear ratio is, however, limited by such factors as starting behaviour and driving quality. Overall downsizing is not merely an engine concept, but represents an efficient combination of the right engine, transmission and vehicle. Under favourable and comparable conditions, fuel econo- my can be improved by approximately $11 \%$. However, this percentage declines with higher vehicle weights.

\section{Combustion}

Prof. Dr.-Ing. S. Pischinger, Dipl.-Ing. K. G. Stapf, Dipl.-Ing. D. Seebach, Dipl.-Ing. C. Bücker, RWTH Aachen; Priv.-Doz. Dr.-Ing. P. Adomeit, Dr.-Ing. J. Ewald, FEV Motorentechnik GmbH, Aachen, reported: "Controlled Auto-Ignition: Combustion Rate Shaping by Mixture Stratification".

Controlled auto-ignition is a promising option for achieving future objectives in the design of gasoline engines. In view of its acoustic behaviour, this combustion process can only be applied under part load and is not suitable for high loads and high speeds. Moreover, a more complex control process is needed for auto-ignition so as to be able to assure self-ignition of the engine. The lecturer explained the different possibilities for regulating both the stratification in the cylinder and the combustion rate of the controlled auto-ignition process.

He also illustrated, in particular, different residual gas strategies and injection times and quantified the resulting stratification in the combustion chamber by means of numerical parameters. He demonstrated the direct correlation between the local distribution of the fuel, air and residual gas in the combustion chamber and the start and duration of combustion. A strongly uneven distribution of the fuel in the combustion chamber results in faster combustion, whereas a strong stratification of the residual gas in the cylinder leads to a retarded, slower combustion.

Dr.-Ing. M. Alt, Prof. Dr.-Ing. U.D. Grebe, J.R. Dulzo, M.S.E.E. V., A. Ramappan, M.S.M.E., GM Powertrain, Pontiac, USA; Dipl.-Ing. P. Kafarnik, GM Powertrain Europe, Rüsselsheim; P. M. Najt, M.S.M.E., GM Research \& Development, Warren, USA, presented: "HCCI - from Lab to the Road".

GM demonstrated the HCCI combustion process in two driveable concept vehicles. Transferring HCCI technology from single-cylinder steady-state engine operation in the laboratory to a modern passenger car had been a significant challenge. Transient HCCI operation has become possible through the development of high-performance electronic engine systems for controlling direct injection and variable valve timing as well as cylinder pressure sensor technology. Variable valve timing controls in-cylinder residual gas and direct injection allows the balancing of cylinders. Robust engine control with a cylinder pressure sensor unit is necessary for compensating the influence of parameters which cannot be changed, such as fuel properties and ambient conditions but which determine the main combustion phase.

The objective of this development is the maximisation of the utilisable HCCI map range so as to achieve better fuel economy for the largest possible number of engine-vehicle combinations. The HCCI combustion concept permits a reduction of fuel consumption of up to $15 \%$ in the European driving cycle as compared to an engine with port-injection without any trade-off in the favourable cost, weight and performance characteristics of gasoline engines. 
Dr.-Ing. W. Steiger, Dr.-Ing. C. Jelitto, Dipl.-Ing. S. Schmerbeck, Volkswagen AG, Wolfsburg, presented: "GCI and CCS - Two New Combustion Systems from Volkswagen".

Within the Volkswagen Group's engine research department various concepts for partial auto-ignition of gasoline engines and partial homogenisation of diesel engines are being intensively studied. Both combustion processes were described and evaluated by the lecturer. The objective is to combine the advantages of low-emission gasoline combustion with the efficiency of the auto-ignition diesel combustion method.

The combination of the two combustion processes is called the CCS combustion method. In this process, fuels are used which have the properties required for this particular combustion method. Volkswagen's research department developed and presented to the public a new innovative combustion process, the GCI combustion method, in 2006 on the basis of a gasoline engine fitted into a vehicle. The lecturer illustrated the GCI combustion process which is used both in freely aspirated and turbo-charged gasoline engines. All technological prerequisites for series production have been met and all necessary steps have been assessed. All results were validated in a research prototype using a conventional three-way catalytic converter, and the maximum permissible emission values were met despite above-stoichiometric GCI operation.

\section{Exhaust Gas Aftertreatment}

Dr. T. Fukuma, T. Asanuma, Dr. N. Ohashi, M. Inoue, K. Ishibashi, Toyota Motor Corporation, Shizuoka, Japan, presented: "Toyota's Diesel Aftertreatment Strategy for Future Emission Compliance“".

Toyota introduced the diesel particulate and $\mathrm{NO}_{\mathrm{x}}$ reduction (DPNR) system based on the Toyota D-CAT concept in the European market in 2003 and continued its development so as to assure compliance with future low emission standards.

Further important improvements were made to the $\mathrm{NO}_{x}$ catalyst material with a view to heightening thermal resistance and the efficiency of the desulphurisation methodology. The high thermal resistance of $\mathrm{NO}_{\mathrm{x}}$ catalysts achieved through $\mathrm{Pt}-\mathrm{O}-\mathrm{Ce}$ bonding results in the suppression of precious metal sintering in order to obtain higher catalytic activity after ageing, especially under lower temperature conditions.

The desulphurisation performance was enhanced through the addition of $\mathrm{TiO}_{2}$ catalyst support material, by assuring overall temperature uniformity in the catalyst and by using rich combustion reduction control in addition to exhaust port injection. Through these improvements, $\mathrm{a} \mathrm{NO}_{\mathrm{x}}$ conversion efficiency of over $70 \%$ was achieved in the new European driving cycle (NEDC) after ageing, which was further raised by means of a sulphur tap catalyst.

A comparison of the improved NSR with Urea SCP solution was carefully investigated in order to decide the future strategy, taking into account $\mathrm{NO}_{\mathrm{x}}$ reduction efficiency, fuel penalty, system costs, vehicle packaging conditions and development times. As a result, it was concluded that NSR was the optimum solution for vehicles in the C and D segments.

Dr.phil.nat. U. Göbel, Dipl.-Ing. W. Müller, Dr.-Ing. I. Grisstede, Dr. rer. nat. F. Rohr, Umicore AG \& Co. KG, Hanau, reported: "Diesel $\mathrm{NO}_{\mathrm{x}}$-Aftertreatment Systems for North America“".

The development of heavy-duty (SUV) passenger cars focuses currently on the introduction of urea-SCR-technology. For medium and light passenger cars, $\mathrm{NO}_{\mathrm{x}}$ storage catalysts are the method of choice. In 2006, the first LNT-based applications which complied with tier 2 BIN standards were launched in North America. The lecturer discussed the main approaches to lower $\mathrm{NO}_{\mathrm{x}}$ emissions in the Volkswagen Jetta 2.0 1 TDI which meets tier 2 and 5/LEV 2 emission standards in North America. He also explained model gas, engine bench and vehicle test results in order to describe the development of an exhaust-gas aftertreatment system with $\mathrm{NO}_{\mathrm{x}}$ storage catalysts. Major objectives in the development of $\mathrm{NO}_{x}$ aftertreatment technologies are the widening of the active temperature window, as well as the improvement of hightemperature stability and desulphurisation characteristics of individual catalytic converter components.

Dr. H.S. Gandhi, Dr. J.R. Theis, Ford Motor Company, Dearborn, USA, presented: "Potential Application of SCR Technology to GDI Engines".

To date, lean $\mathrm{NO}_{\mathrm{x}}$ traps (LNT) have been used on GDI engines for lean $\mathrm{NO}_{\mathrm{x}}$ control. Selective catalytic reduction (SCR) with $\mathrm{NH}_{3}$ has several advantages over a LNT, including a broader temperature window and increased robustness to the feedgas $\mathrm{NO}_{\mathrm{x}}$ level. SCR catalysts also do not need the rich purges required by $\mathrm{NO}_{\mathrm{x}}$ traps. Finally, SCR catalysts use inexpensive base metals instead of the precious metals used in $\mathrm{NO}_{\mathrm{x}}$ traps. However, a concern was that hot rich exhaust conditions (e.g., during trailer tow) could degrade the zeolite based SCR catalysts being developed for mobile applications. Therefore, laboratory samples of an iron/zeolite SCR catalyst and a copper/zeolite SCR catalyst were aged at high temperatures using different $\mathrm{A} / \mathrm{F}$ ratio schedules. Both SCR formulations exhibited high $\mathrm{NO}_{x}$ performance after ageing, indicating that both catalysts were sufficiently durable for GDI engines. The effects of sulphur on the SCR catalysts were investigated. An optimised combination of $\mathrm{Fe}$ and $\mathrm{Cu} \mathrm{SCR}$ catalysts provided robust $\mathrm{NO}_{\mathrm{x}}$ performance with different $\mathrm{NO}$ concentrations at different temperatures. Finally, the effects of the $\mathrm{NH}_{3} / \mathrm{NO}$ ratio on the $\mathrm{NO}_{x}$ conversion and $\mathrm{NH}_{3}$ slip were evaluated.

\section{Hybrid / Otto - Diesel}

Dipl.-Ing. O. Bitsche, Dipl.-Ing. J. Schenk, Dr. N. Armstrong, Dipl.-Ing. O. Vollrath, Dipl.-Ing. P. Antony, Daimler AG, Stuttgart, presented: "Premium Hybrids - Scenarios and Solutions of Mercedes-Benz".

Increasingly stringent ecological and economic demands made upon engines and transmission systems call for the use of electric propulsion technology in drivetrains. By designing modular components specific to hybrid vehicles, such as start/stop systems, integrated electric 
motors, high-performance electronics, scaleable battery systems, and auxiliary equipment, a wide range of different degrees of hybridisation can be achieved. MercedesBenz has created a broad platform for hybridisation which is adjustable to all powertrains and the specific character of its model lines.

Prof. A.E. Catania, Prof. E. Spessa, Politecnico di Torino, Dr. V. Paladini, Dr. A. Vassallo, General Motors Powertrain Europe, Torino, presented: "Influence of Hybrid Operation on Fuel Consumption and Emissions for Micro-, Mild- and Strong-Hybrid Diesel Applications".

The potential of improved fuel economy and the challenges of exhaust gas emissions for micro, mild and full hybrid applications in light-weight commercial vehicles based on the GM 1.9 Litre 4-cylinder in-line diesel engines were studied in a number of experiments. Optimised hybrid cycles were simulated on a dynamic engine test bench and the findings were subsequently compared with a conventional base engine.

It was found that hybridisation also makes sense in combination with highly efficient internal combustion engines (diesel). The micro hybrid has approximately $4 \%$ better fuel economy, the mild hybrid (i.e. starter-generator) consumes approximately $10 \%$ less fuel and the full hybrid (power split) allows a $14 \%$ reduction of fuel consumption. Hybridisation can also influence exhaust gas emissions. Furthermore, it became obvious that the chosen system affected the composition of the exhaust gas. By reducing the number of idling parts of the engine, $\mathrm{HC}$ and $\mathrm{CO}$ emissions in particular were generally lowered. In contrast, full hybrid engines are characterised by higher $\mathrm{NO}_{\mathrm{x}}$ and $\mathrm{PM}$ emissions which called for an adjustment of the engine calibration, so that the emission levels assumed for the initial applications could be reached. This goes to show that hybridisation, especially full hybrids, is not a plug-in - and play solution. Much rather, it is necessary to integrate hybrid systems into design.

Dr.-Ing. R. Marquard, Dr.-Ing. Dipl.-Wirt, Ing. A. Hanenkamp, MAN Diesel SE, Augsburg, presented: "The MAN 32/40 PGI, a Synthesis of the Otto and Diesel Cycles".

Power plants with large gas engines can be operated with optimum efficiency on account of their basic thermodynamic processes. Large diesel engines with their high potential for mean pressure values, high compression ratios and favourable turbocharging conditions are configured to serve as base engines. The lean air-gas-fuel mixture is ignited either by means of a spark plug or through auto-ignition after the injection of a small volume of diesel. At higher mean pressure rates, the ignition energy of the spark plugs must be dramatically raised, resulting in a disproportionately rapid wear of the plugs. Therefore, the utilisation of the existing mean pressure potential appears problematic for cost reasons. The performance gas injection method (PGI) developed by MAN uses high ignition energy for igniting very lean mixtures. This process assures low $\mathrm{NO}_{\mathrm{x}}$ emissions combined with high efficiency. In addition, the PGI process permits a widening of the operating window, as extremely lean mixtures can be used.

\section{Powertrain}

Dipl.-Ing. F. Eichler, Dipl.-Ing. A. Fürschuss, Dr.-Ing. M. Hart, Dipl.-Ing. R. Schaich, Dipl.-Ing. B. Tschamon, Dipl.-Ing. R. Illenberger, Dipl.-Ing. M. Glose, Dipl.-Ing. W. Zimmermann, Mercedes-AMG GmbH, Affalterbach, presented: "The Powertrain for the New C63 AMG".

Based on the AMG M156 engine which was first installed in the ML 63 launched in December 2005, a strongly performance - oriented and emotional concept was conceived in combination with the NA 6.2 7-speed converter transmission.

The large 6.2 Litre M156 engine is the first engine that was exclusively developed by AMG and has no features of the base engine designed by the parent company Daimler. The engine is characterised by low specific weight, outstanding power and torque values as well as excellent revving behaviour despite its large displacement cylinders. Special attention was given to efficient combustion and a high degree of mechanical efficiency. The LDS process, which was used for cylinder wall coating for the first time in a production engine, combined with an extremely sturdy liner structure, contributed significantly to the engine's outstanding features. Thanks to the space-saving design of the cylinder heads, as well as the special crankshaft configuration and the high degree of integration of the individual systems, the engine is very compact given its large displacement.

Dr.-Ing. L. Spiegel, Dipl.-Ing. M. Kerkau, Dipl.-Ing. G. Bofinger, Dipl.-Ing. S. Müller, Dipl.-Ing. R. Meier, Dr.-Ing. H.-J. Neußer, Dr. Ing.h.c.F. Porsche AG, Weissach, reported: „Powertrain Management in Sports Cars in order to Reduce Fuel Consumption".

The lecturer explained Porsche's design philosophy by describing the technological potential for conceiving a typical sports car engine. The drive management system co-ordinates all technological options which were realised in order to obtain a sporty and efficient drive. Drivers can choose whether they want to use either a standard or sporty operating mode. In addition, a thermo-management system was developed with a view to optimising the engine warmup phase, and part-load as well as full-load operation, so as to match the characteristics of sports cars. The lecturer described in detail the potential of an idling/stop system and its complex integration into the vehicle. Adaptive switching strategies, he explained, are used in automatic transmission for the automatic selection of the switching time for optimising fuel consumption and performance.

Dipl.-Ing. M. Bek, Dipl.-Ing. P. Schiele, ZF Getriebe $\mathrm{GmbH}$, Friedrichshafen, presented: "Hydraulic Impulse Oil Storage - How ZF Automatic Transmissions Contribute to $\mathrm{CO}_{2}$ Reduction".

With the development of an eight-speed transmission series, ZF has made a substantial contribution to higher fuel economy and the reduction of $\mathrm{CO}_{2}$ emission levels. Alongside modifications to the transmission, the eight-speed series also offers an option for the use of an engine start/stop function which turns off the engine when the vehicle stops, thus avoiding fuel consumption during idling. 
The option to use the start/stop function has led to a further improvement of fuel efficiency of approximately 5\% in the NEDC (New European Driving Cycle).

\section{New Otto Engines}

Dr. M. Bollig, Dr. H. Haas, Dr. G. Kiesgen, Dipl.-Ing. O. Moirano, Dipl.-Ing. J. Schopp, Dr. A. Schueers, BMW Group, Munich, presented: "The New High-Performance Variant of the New Small 4-Cylinder Engine Family for the MINI Cooper S Works".

Under the lead of BMW and in cooperation with PSA, the new four-cylinder engine family was developed. To date it has covered four different performance categories featuring two different technologies which are used in varying numbers by BMW and PSA. On the basis of this engine family, BMW designed its own high-performance version with an output of $155 \mathrm{~kW} / 260 \mathrm{~N} \cdot \mathrm{m}$ for the new Mini Cooper Works, which will be exclusively used in the Mini. The lecturer illustrated the development objectives, and the modifications that were made leading to the results with regard to the engine's functionality and acoustic behaviour.

Dipl.-Ing. M. Fitzen, Dipl.-Ing. W. Hatz, Dipl.-Ing. Axel E., Dr.-Ing. T. Heiduk, Dipl.-Ing. J. Riegner, Audi AG, Ingolstadt, reported: "The Audi 3.0 Litre TFSI - the New Top-of-the-Range V6 Engine“.

The 3.01 TFSI represents Audi's new top-of-the-range V6 engine. In its basic form this engine design delivers 213 $\mathrm{kW}$ and $420 \mathrm{~N} \cdot \mathrm{m}$. The fundamental design of the engine was taken over from the naturally aspirated V6 engines as revised in 2006, including measures to reduce friction losses. An entirely new development is the supercharger module, with integrated Roots blower, bypass regulation and charge air cooling. All components are accommodated inside the $\mathrm{V}$. As a result of the extremely compact dimensions it has also been possible to take over the arrangement of the inlet and exhaust systems directly from the naturally aspirated engines without any changes. In conjunction with direct injection, this engine sets new standards in terms of responsiveness, efficiency and acoustic behaviour. The new Audi V6 3.0 Litre TFSI combines excellent torque and power output with outstanding responsiveness, while offering the same package and exhaust-related benefits as naturally aspirated engines. Thus it is ideally suited for a wide range of applications within the Audi model portfolio.

Dipl.-Ing. K. Joos, Dipl.-Ing. P. Lückert, Dipl.-Ing. F. Kreitmann, Dr.-Ing. N. Merdes, Dr.-Ing. R. Weller, Dipl.Ing. E. Rau, Daimler AG, Stuttgart, presented: 'New MercedesBenz V6 Sports Engine - The Sporty Way to Save Fuel“.

Since spring 2004, the V6 gasoline engine with its internal model designation M 272 has been series-produced by Mercedes-Benz. This six-cylinder engine is installed in all Mercedes-Benz passenger cars with standard and fourwheel drive, without any technical variations. As part of a model refinement package, this 3.5 Litre, V6 engine was developed within a period of only 21 months for the SL and SLK roadster model series in order to accentuate the sporty character of these cars. The goal was to combine sporty performance with a wide rpm range, markedly increased power output, sporty acoustic behaviour and significantly better fuel economy.

In order to meet all of these criteria, the chain drive and valve train were modified and the gas exchange system and the combustion chamber were entirely redesigned. By maintaining the favourable cylinder charge values, combustion chamber turbulence was drastically modified. In combination with improved fuel-air mixture formation, as well as a higher compression ratio, both engine output and efficiency were raised.

\section{Engine Mechanics}

J. Harada, T. Yamada, K. Watanabe, Toyota Motor Corporation, Japan, presented: "The New L4 Gasoline Engines with VALVEMATIC System".

Toyota developed a continuously variable valve timing and lift control system called "Valvematic". By implementing this system, fuel consumption can be improved as a smaller valve lift is used under low and middle engine loads (reduction of pumping loss by closing the intake valve earlier).

The system uses a special rocker arm for continuously variable valve timing and lift. It is located between a conventional roller-rocker arm and the camshaft. An electrically actuated motor controls the lift and valve opening time, whereas a hydraulic controlled variable valve timing mechanism (VVT-i) is also arranged on both the intake and exhaust camshafts.

The newly developed actuator contains Toyota's original planetary roller screw unit translating rotary movement of the motor into linear actuation. Thanks to the alignment of rocking centre and actuator drive direction, a compact design has been achieved.

In 2007, Valvematic was introduced on the Japanese market on a 2.0 litre engine (3ZR-FAE), which has the largest displacement of the ZR series. The engine employs a cam housing structure with a valve-train system separated from the cylinder head. This structure allows the use of a large number of common parts with the conventional engine, and an easy mounting of the Valvematic system by changing only the cam housing assembly.

Thanks to the integrated control of Valvematic, VVT-I and the throttle valve, the fuel consumption of this engine was lowered by 5 to $10 \%$.

Maximum power was also improved by approximately $11 \mathrm{~kW}$ thanks to optimised volumetric efficiency by means of the Valvematic system. Furthermore, exhaust emissions were lowered due to the increased induction flow rate into the cylinders at smaller valve lift operating conditions.

T. Fujita, S. Kiga, Nissan Motor Co., Ltd., S. Tsuruta, Hitachi, Ltd., Kanagawa, Japan, presented: ,The Innovative Variable Valve Event and Lift System (VVEL) for the New Nissan V6 and V8 Engine“.

Nissan has recently developed a new variable valve event and lift (VVEL) system that continuously controls both the intake valve lift and the event angles (valve opening and closing timing) over a wide range. Combined with the conventional VTC technology, this VVEL system optimally 
controls the intake valve timing and lift for matching engine operating conditions. This technical specification enables thus to achieve well-balanced improvement for major performance of engines.

This paper describes the basic configuration of the VVEL system, its electrical control system as well as the effects involved for improving the overall engine performance. Moreover, it also explains the production technology for the applying expansion from V6 to V8. At the same time, the future view of this VVEL technology is introduced.

Dr. H. Unger, Dr. J. Schneider, Dr. C. Schwarz, Dr. K.-F. Koch, BMW Group, Munich, presented: "VALVETRONIC - Experience from seven Years of Series Production and a Look into the Future“".

With its new four-cylinder engine, BMW in 2001 launched the first car petrol engine to use a fully variable valve train, BMW Valvetronic, to control engine load. This resulted in a reduction in fuel consumption by $12 \%$ as compared to its predecessor and created the base technology for all future BMW petrol engines. Since its launch, Valvetronic has been continually developed and will meet all requirements and realise further potential in the future.

Thanks to the potential of the Valvetronic, thermodynamics have been improved and contributed significantly to higher fuel economy. In addition, it offers large future potential for the reduction of fuel consumption in combination with other new technologies, such as homogeneous direct injection and turbo-charging.

The manufacture of a system such as the $\mathrm{v}$ in series production was, and remains, at least as big a challenge for automotive engineers as was its initial design and development. BMW has already produced and sold over 2.5 million engines with the Valvetronic system.

\section{Closing Session: View into the Future}

Prof. Dr. M. Winterkorn, Chairman of the Board of Management, Volkswagen AG, Wolfsburg, discussed: "Sustainability and Mobility - Challenges Involved in the Development of New Powertrain Technologies in the Volkswagen Group".

He said: "We at Volkswagen consider sustainability not only as a challenge but primarily as an opportunity" and drew special attention to the following areas:

- "Technologies like the TDI, TSI and TFSI and our doubleclutch transmission systems, first launched in Europe, are conquering the world".

- New concepts such as Blue Motion or eco-fuel driven vehicles, the diesel hybrid or alternative fuels like Sun Fuel will be widely used in regional applications.

- "With the new compact family we have an entirely new vehicle generation which will set new standards in terms of environmental friendliness".

F. Fehrenbach, Chairman of the Board of Management, Robert Bosch GmbH, Stuttgart, presented: "The Challenges Facing Global Suppliers".

The key challenges facing global suppliers in the automotive industry can be summarised as follows:
- Changes in the global economy, the regional redistribution of gross domestic products (GDP) and shifts in global automobile production will strengthen the economies of the Asia Pacific region, in particular.

- The increase in the oil price, exchange rate risks, rising prices for raw materials, and the automotive industry's relatively negative annual price trends call not only for ever higher productivity, but also for considerable global innovative strength, with greater regional expertise.

- The future challenges resulting from the need to reduce emission levels further also require greater technological expertise and innovative strength.

- The low-price category is opening up completely new market segments. These also require completely new technological solutions which, together with the optimisation of emissions, will significantly increase technological diversification and general complexity.

- But the desire to minimise emissions is not everything. There is also the vision of accident-free driving. Here again, one of the main ways to achieve this is through the innovation of components and systems.

- Standardisation, the classical solution for reducing complexity, must be brought into line with customer requirements, which differ greatly from region to region.

Dr. D. Zetsche, Chairman of the Board of Management, Daimler AG, Stuttgart, presented: "For the Love of Inventing: Innovation as Engine of Growth in the Auto Industry".

Carl Benz once said: "The passion for invention never ends". This sentence applies not only to Daimler, but to the entire automotive engineering industry. The "passion for invention" remains one of the most important driving forces in the automobile industry.

Individual mobility has been significantly enhanced by the automobile. In the 19th century, the average European travelled just $20 \mathrm{~km}$ in the course of a year, today the equivalent number is $20 \mathrm{~km}$ per day. Thanks to the automobile we are less dependent on distances from one place to another and can thus virtually "drive towards" new potential developments. A car liberates - it gives people the freedom to choose where they live, where they work, how they spend their leisure time, and so on. It gives people a wider choice. This is why the spread of the automobile is often synonymous with democratisation. As a result, the 20th century is rightfully known as the "century of the automobile". But let us bear in mind that what we have witnessed was only the first century of the automobile; the second has just begun.

The papers presented at the 29th International Vienna Motor Symposium are contained in the VDI progress reports (VDI Fortschritt-Berichte), series 12, no. 672.

\section{Artykut recenzowany}

Univ.-Prof. Dr. techn. Hans Peter Lenz - President of the Austrian Society of Automotive Engineers (ÖVK) in Vienna, Austria.

Prof. dr Hans Peter Lenz - przewodniczqcy Austriackiego Stowarzyszenia Inżynierów Motoryzacji (ÖVK).

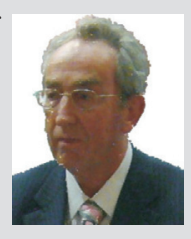

